\title{
Aplicabilidade dos direitos das parturientes: do paradigma à realidade
}

\author{
Natália Timm Aires ${ }^{1}$, Sonia Maria Kongzen Meincke ${ }^{2}$, Ana Candida Lopes Corrêa ${ }^{3}$, Camila Neumaier Alves ${ }^{4}$, \\ Rita Fernanda Monteiro Fernandes ${ }^{5}$, Josiane Santos Palma ${ }^{1}$, Greice Carvalho de Matos ${ }^{1}$, Marilu Correa Soares ${ }^{1}$
}

\begin{abstract}
RESUMO
Objetivo: conhecer a aplicabilidade dos direitos das parturientes pelos profissionais de saúde, durante o trabalho de parto e parto em hospitais de ensino de um Município do Sul do Estado do Rio Grande do Sul. Método: estudo qualitativo realizado com quatro profissionais da saúde trabalhadores do centro obstétrico de dois hospitais. A coleta de dados ocorreu por meio de entrevista semiestruturada. Os dados foram analisados de acordo com a proposta operativa. Resultados: a aplicabilidade das Leis era limitada e justificada pela falta de conhecimento daqueles que atuavam nos centros obstétricos e pela carência de investimento na sensibilização dos profissionais da saúde quanto a temática abordada. Conclusão: apesar da existência de diferentes programas e políticas que preconizam a melhoria na qualidade da assistência a mulher, desde a concepção até o parto e puerpério, ainda é necessário aprimorar a aderência dos profissionais às práticas humanizadas na atenção aos direitos das parturientes.
\end{abstract}

Descritores: Assistência a saúde; Gravidez; Parto Humanizado; Enfermagem

\section{Applicability of the rights of postpartum women: of the paradigm to the reality}

\begin{abstract}
Aim: to know the applicability of the rights of pregnant women by health professionals during labor and delivery, in hospitals of a city south of Rio Grande do Sul. Method: qualitative research realized with four health professional of obstetric center. The data collection were through semi-structured interviews during the months of october and november 2013. The data were analyzed according to the operative proposed. Results: the applicability of the Laws was limited and justified by the lack know ledge about those Laws and the low investment in the education of professionals. Conclusion: despite the existence of programs and policies that advocate improved quality of care for women, from conception to the postpartum, is still necessary to improve adherence of professional to the humanized attention to the rigths of postpartum women.
\end{abstract}

Descriptors: Delivery of Health Care; Pregnancy; Humanizing Delivery; Nursing.

\footnotetext{
${ }^{1}$ Enfermeira graduada pela Universidade Federal de Pelotas (UFPEL), Pelotas, RS, Brasil.

${ }^{2}$ Doutora em Enfermagem pela Universidade Federal de Santa Catarina (UFSC), Florianópolis, Santa Catarina, Brasil.

${ }^{3}$ Mestre em Ciências da Saúde pela Faculdade de Enfermagem da Universidade Federal de Pelotas (UFPEL), Pelotas, RS, Brasil.

${ }^{4}$ Enfermeira Graduada pela Universidade Federal de Santa Maria (UFSM), Santa Maria, RS, Brasil.

${ }^{5}$ Mestre em Enfermagem da Universidade Federal de Pelotas (UFPEL), Pelotas, RS, Brasil.
} 


\section{Introdução}

O período gravídico-puerperal é permeado por inúmeros acontecimentos de ordem biopsicossociais, os quais necessitam de atendimento especializado e qualificado a fim de assegurar um momento seguro para a mulher e sua família durante o parto e nascimento. Neste contexto, a assistência ao parto de forma medicalizada e tecnicista causa sofrimento físico e emocional desnecessário à mulher, o que pode impedir a queda dos índices de morbimortalidade materna e perinatal ${ }^{1}$.

A trajetória histórica de cuidado ao trabalho de parto e parto está ancorada ao ambiente domiciliar, no qual a parturiente era assistida por outra mulher, geralmente uma parteira de sua confiança, e apoiada pelos seus familiares. Entretanto, no século XX, com o objetivo de reduzir as altas taxas de mortalidade materna e perinatal, ocorreu a institucionalização do parto, trocando o domicílio da mulher pela hospitalização, e consequente medicalização².

Acredita-se que a assistência ao parto está em evidência atualmente por apresentar-se medicalizada e hospitalocêntrica, o que pode contribuir para que os profissionais da saúde engajados na busca de qualificar esta atenção atuem pela constituição dos direitos da parturiente, proporcionando informações e orientações. Corrobora estudo ${ }^{3}$ ao destacar que se as mulheres estivessem cientes dos seus direitos seriam mais exigentes, menos passivas, mais atuantes e menos submissas às condutas tecnicistas que são submetidas na atenção ao ciclo gravídico-puerperal.

Neste ínterim surgiu o termo "Humanização do Parto". A humanização do parto visa substituir as intervenções mecanicistas e o uso abusivo de tecnologias, por um cuidado que preserve o caráter fisiológico do parto e nascimento, contemplando um conjunto de condutas e procedimentos que tornem este processo mais saudável, assim prevenindo a morbimortalidade da mulher e do recém-nascido 4 .

O cuidado humanizado está alicerçado na capacidade de detectar, sentir e interagir com as mulheres e seus familiares; quando se constitui uma relação de respeito ao ser humano e aos seus direitos. Para tanto, para que ocorra a humanização do parto é necessário que os direitos das parturientes e as diretrizes preconizadas pelo Programa de Humanização sejam respeitados e aplicados pela equipe profissional ${ }^{5}$. Desta maneira, destacam-se neste estudo, as Leis referentes ao direito de acompanhante, de conhecimento e vinculação prévia a maternidade.

As práticas em saúde, de acordo com o Ministério da Saúde, deverão nortear-se pelo principio da humanização, compreendido como atitudes e comportamentos do profissional de saúde que contribuam para reforçar o caráter da atenção à saúde como direito, que melhorem o grau de informação das mulheres em relação ao seu corpo e suas condições de saúde, ampliando sua capacidade de fazer escolhas adequadas ao seu contexto de vida ${ }^{6}$.

É indispensável para uma experiência positiva do parto, a certeza de que a mulher foi protagonista deste evento, tendo seus direitos respeitados nos estabelecimentos de saúde que lhe prestaram assistência, de forma a proporcionar sua segurança e bem estar, assim como o do recém nascido. Acrescenta-se a importância da parturiente ser estimulada e sensibilizada da necessidade dela ser um sujeito ativo e participante de todo o processo, e não agente passivo das técnicas médicas, como se vê habitualmente ${ }^{7}$.

A partir destas reflexões vislumbrou-se a seguinte questão norteadora: "qual a aplicabilidade dos direitos das parturientes durante o trabalho de parto e parto em hospitais de ensino, em um Município do sul do Estado do Rio Grande do Sul?" Para tanto, o objetivo foi conhecer a aplicabilidade dos direitos das parturientes pelos profissionais de saúde, durante o trabalho de parto e parto em hospitais de ensino de um Município do Sul do Estado do Rio Grande do Sul.

\section{Metodologia}

Trata-se de uma pesquisa qualitativa, de caráter exploratório e descritivo. 0 cenário de estudo foi composto por duas Unidades Obstétricas de Hospitais de ensino de um Município do Rio Grande do Sul. Tais unidades atendiam exclusivamente pelo Sistema Único de Saúde (SUS).

Ressalta-se que, inicialmente, a proposta do estudo era abarcar as três unidades obstétricas existentes no município, entretanto uma delas decidiu por não se inserir na pesquisa. Desta forma, os informantes que aceitaram participar do estudo consistiram de quatro profissionais da saúde, trabalhadores das referidas unidades, entre estes Médicos e Enfermeiros. Os critérios de inclusão compreendiam ser Enfermeiro ou Médico que desenvolvessem atividades no centro obstétrico; e tivessem vínculo empregatício há no mínimo um ano com a instituição cenário do estudo (considerando que este período seria suficiente para os profissionais estarem mais adaptados ao emprego e ao atendimento às mulheres). 
A coleta de dados foi realizada entre os meses de outubro e novembro de 2013 por meio de entrevista semiestruturada. $O$ teor das entrevistas foi integralmente transcrito, subsidiado pela proposta operativa de Minayo ${ }^{8}$, que compreende a pré-análise, exploração do material, resultados obtidos e interpretação. Para a fase de pré-análise, primeiramente foi reunido todo o material empírico, realizada uma leitura minuciosa e exploração do conteúdo das entrevistas, após foi confrontado os objetivos iniciais com os dados coletados por meio de leituras.

$\mathrm{Na}$ exploração do material, os dados foram codificados e categorizados. Durante esta etapa os conteúdos foram agrupados conforme os temas significantes para a questão norteadora da pesquisa. Após, os resultados obtidos e a interpretação foram realizados, confrontados com a literatura.

Os princípios éticos que nortearam esta pesquisa foram correspondentes a Resolução n 466/2012 do Conselho Nacional de Saúde, do Ministério da Saúde, que dispõe sobre Pesquisas com seres humanos ${ }^{9} \mathrm{O}$ Projeto obteve anuência por Comitê de Ética em Pesquisa sob o parecer $n^{0}$ 424.081. A fim de manter 0 anonimato dos participantes, estes foram identificados PS (Profissional da Saúde), seguidos pelo número da ordem das entrevistas (PS1, PS2, PS3, PS4).

\section{Resultados e discussão}

Apresenta-se o perfil dos profissionais participantes do estudo. A idade dos profissionais variou entre 23 e 47 anos, com predomínio de tempo de formação menor que 3 anos, assim como o tempo de trabalho na instituição.

A seguir apresentam-se o conhecimento e a aplicação dos direitos das parturientes, evidenciados neste estudo. Destacam-se as Leis referentes ao direito de acompanhante e visita prévia a maternidade.

Com a instituição da Lei 11.108 em abril de 2005, o Ministério da Saúde iniciou um movimento de reorganização dos centros obstétricos e dos profissionais de saúde atuantes nesta área. A finalidade desta Lei é proporcionar à parturiente, que ao ser recebida em uma instituição, tenha garantia de um atendimento humanizado, no qual o parto venha a ocorrer de forma natural e sem intervenções desnecessárias, com o benefício do acompanhante ${ }^{10}$.

Entretanto, os participantes do estudo não conheciam a Lei pelo seu número de identificação, como visto a seguir:

Não conheço, nunca ouvi falar (PS1).

Não conheço nada (PS2).

Ao serem informados que se tratava de uma lei que garante o direito da parturiente de acompanhamento durante o trabalho de parto, parto e pós-parto imediato, mostraram um conhecimento superficial sobre o seu conteúdo. Evidenciado nas seguintes falas:

Sei que a parturiente tem direito a um acompanhante, mas não é sempre que nós conseguimos garantir que isto aconteça, acredito que seja muito importante pra segurança da paciente na hora do parto (PS3).

Essa lei nós conhecemos sim, nós temos conhecimento e procuramos botar em prática (PS4).

Observa-se que há conhecimento acerca de alguns aspectos relativos às Leis que garantem os direitos das parturientes e buscam a humanização do atendimento, especialmente no tocante à participação de um acompanhante no momento do parto. Em vista desta perspectiva, autores entendem que aspectos ligados à organização dos serviços de saúde e ao desenvolvimento da assistência às parturientes, especialmente quanto à humanização do processo de parturição, são desafios encontrados para a implementação dos direitos das parturientes ${ }^{11}$.

Contudo os participantes do estudo relataram que convidavam os pais a assistirem o parto, porém alguns deles não queriam acompanhar ou não sentiam-se bem em permanecer na sala de parto. 
Os pais normalmente ficam muito nervosos e não aguentam ver a companheira sentindo dor, muitas vezes desmaiam ou passam mal (PS3).

Durante o processo de parturição, é normal a parturiente sentir medo, insegurança e necessitar a presença de um acompanhante de sua confiança, para ficar ao seu lado durante o trabalho de parto e o parto. A pessoa que acompanha a mulher precisa estar apta para the oferecer apoio emocional e segurança, a fim de transformar o parto em uma experiência positiva para a mulher ${ }^{12}$.

Seguindo este contexto, destaca-se que a presença de um acompanhante durante o trabalho de parto e parto depende do contexto social, da política de saúde do país e de sua legislação, mas principalmente da filosofia adotada pela equipe de

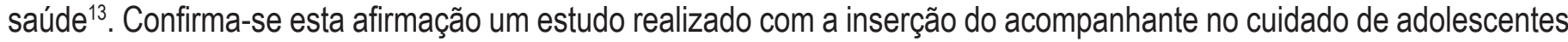
em um centro obstétrico, ao observar que nas práticas desses setores, em sua maioria, o acompanhante é permitido na sala de pré-parto, mas no momento em que a parturiente é encaminhada até a sala de parto, o acompanhante é impedido de entrar e participar deste momento ${ }^{14}$.

A participação limitada do acompanhante é decorrente do modelo de assistência intervencionista ao parto e dos preconceitos frente à possibilidade de um acompanhante ativo. Esses dois pontos influenciam também na falta de compromisso dos profissionais em acolher e inserir o acompanhante no processo do nascimento. Assim, se estabelece uma relação de poder do corpo da mulher e domínio da situação por parte da equipe de saúde ${ }^{15}$.

Outra questão abordada nesta pesquisa foi a Lei de 27 de dezembro de 2007, a qual assegura que toda parturiente assistida pelo Sistema Único de Saúde (SUS), tem direito a conhecimento e vinculação prévia à maternidade na qual será realizado seu parto, e a maternidade na qual será atendida em caso de intercorrências ${ }^{16}$. Entretanto, durante a entrevista, quando questionados acerca da Lei $n^{0} 11.634$, os profissionais não a reconheceram por sua identificação:

Não conheço nada. (PS2)

Não tinha conhecimento dessa lei. (PS4)

Todavia, ao ser esclarecido que seu conteúdo refere-se ao direito da parturiente de vinculação e conhecimento prévio a maternidade a qual receberá assistência, dois dos participantes a reconheceram, como visto a seguir:

Conheço que a parturiente tem o direito de procurar a maternidade, mas essa lei é pouco divulgada, na verdade nunca li sobre ela, apenas ouvi falar (PS3).

[...] quando eu participei do grupo de parturiente, trouxe as parturientes para conhecer a maternidade [...] elas se espantaram com o funcionamento, porque para elas era outra coisa, e então elas gostaram muito (PS2).

A partir destas falas percebe-se que os participantes possuíam conhecimento acerca dos textos referentes à legislação, porém não os vincularam a uma Lei específica. Tal situação talvez possa dever-se ao fato do desconhecimento e pouca divulgação dos direitos das parturientes nestas instituições e pela ausência de interesse desses profissionais em conhecêlas, já que, conforme PS3 já ouviu falar da Lei, porém nunca a leu.

A introdução dos direitos das parturientes aos profissionais de saúde é uma condição imposta, a qual não tem investimento informativo para preparar estes profissionais a incorporarem seus preceitos na humanização do parto. ${ }^{17}$ Entende-se que a implementação dos direitos das parturientes requer o envolvimento e a aderência dos profissionais da saúde, assim como o entendimento de que a forma de como o parto é assistido e vivenciado pela mulher pode ser decisiva para a promoção de uma maternidade segura.

Além deste aspecto, os profissionais relataram que poucas parturientes procuravam conhecer a maternidade, o que pode estar atrelado a falta de divulgação deste direito e pouca informação durante o pré-natal nas Unidades Básicas de Saúde (UBS).

[...] poucas parturientes procuram conhecer a nossa maternidade, mas quando querem conhecer eu me disponibilizo a mostrar tudo - a sala de pré-parto, a de parto, onde é a recepção do RN, e também a equipe de enfermagem [...] (PS3). 
[...] nem os profissionais, nem as parturientes conhecem esse direito, então esse conhecimento prévio da maternidade não acontece (PS4).

A falta de conhecimento por parte dos profissionais e das parturientes sobre o direito de vinculação e conhecimento prévio da maternidade implica na não aplicabilidade desta Lei. Embora todo profissional que atue nos centros obstétricos vinculados ao SUS tem o dever de acolher a parturiente (apresentar a maternidade, a equipe que possivelmente lhe prestará assistência, assim como explicar os procedimentos e onde seu filho será recebido), percebe-se que essa realidade ocorre de forma parcial nos serviços de saúde pesquisados.

Para mudar a prática em relação ao nascimento é preciso humanizar a assistência desde o pré-natal e esta mudança poderá iniciar-se pelo profissional de saúde ao oferecer maiores informações as parturientes e seus familiares ${ }^{3}$.

A promulgação de uma Lei não garante sua aplicabilidade, sendo evidente a necessidade de sensibilização dos profissionais, bem como orientação dos usuários do SUS sobre seus direitos. A instituição hospitalar é responsável pelas ações de atenção à saúde das pessoas e regulariza as rotinas que os profissionais desenvolvem quando prestam 0 cuidado. Muitos profissionais de saúde têm competência técnica e autonomia legal para oferecer os cuidados necessários a parturiente, porém não podem cumprir esse direito porque estão presos a uma rotina organizacional em que devem aceitar as decisões e ações para prestar assistência a população ${ }^{17}$.

É essencial a reorganização dos serviços de saúde. A reorganização do ambiente hospitalar requer mudanças no foco da assistência, passando de centrado no serviço, na rotina imposta para ser centrado na parturiente e sua família ${ }^{3}$.

Neste contexto, para a garantia de um parto efetivamente humanizado, é primordial a aplicação, por parte dos profissionais e dos serviços de saúde, dos direitos das parturientes. Em vista do exposto, no transcurso da pesquisa ocorreram relatos referentes à aplicabilidade dos direitos por parte desses profissionais:

[...] nesta instituição o enfermeiro não tem autonomia [...] na hora do parto quem manda são os médicos ou os preceptores dos residentes. (PS3).

Refletindo sobre esta fala, nota-se que a hierarquização da assistência ao parto, e falta de autonomia do enfermeiro nos centros obstétricos, é afirmada como um obstáculo para a garantia do direito da parturiente e efetivação da humanização do parto. $O$ trabalho em equipe e a troca de saberes é um incentivo para a assistência a mulher de forma integral e humanizada, assim como a aplicação dos direitos das parturientes ${ }^{17}$.

Outras dificuldades relatadas neste estudo referem-se à estrutura física dos hospitais e das condições emocionais dos acompanhantes, que por vezes podem atrapalhar o momento do parto e nascimento:

A principal dificuldade é a estrutura física oferecida principalmente na sala do pré-parto, porque as parturientes estão expostas, não tem uma divisão entre as camas, se tivesse um biombo que dividisse daí ficaria melhor, precisamos manter a privacidade. (PS1).

[...] tem mães que quando vêema filha sentindo dor, entram em pânico e começam a dizer que tem que fazer cesárea [...] e a própria parturiente acaba ficando preocupada [...] este tipo de acompanhante atrapalha (PS4).

Embora a presença do acompanhante seja uma recomendação do Ministério da Saúde, observam-se, em alguns serviços de saúde, obstáculos a sua participação, justificados pela inadequada infraestrutura e, principalmente, pela falta de preparo da equipe de saúde para lidar com essa recomendação ${ }^{18}$, uma vez que eles podem "atrapalhar" o momento do nascimento.

Essa dificuldade foi igualmente realçada em estudo realizado no Sul do Brasil onde as autoras constataram que uma das justificativas para o não cumprimento da legislação poderia ser a infraestrutura física inadequada, não favorecendo a privacidade tanto das parturientes, quanto de seus acompanhantes ${ }^{3}$.

Outro aspecto evidenciado nas entrevistas refere-se à dificuldade que as equipes de saúde têm em preparar as parturientes no pré-natal, e o parto acontecer em uma instituição diferente da que foi orientada.

[...] muitas parturientes que realizam o pré-natal conosco, e participam do nosso grupo de parturiente, vão ganhar em outra instituição [...] não é certo qual vai ser a maternidade, daí fica um trabalho em vão (PS3). 
Outra dificuldade é que embora a parturiente conheça a nossa maternidade, não é certo que ela vá ganhar seu filho aqui. (PS2).

Nota-se nas falas, que a maior dificuldade era a incerteza de qual maternidade a parturiente receberia assistência. Frente a essa condição, percebe-se que a criação do vínculo prévio com a equipe é dificultada, pois a mulher estabelece o contato com a equipe de uma instituição, porém pode ser encaminhada para outra diferente na hora do parto. Para a concretização da atenção de qualidade e humanizada, é dever dos serviços e dos profissionais de saúde acolher com dignidade a mulher e o recém nascido, enfocando-os como sujeitos de direitos ${ }^{3}$.

A não aplicabilidade dos direitos das parturientes provém da falta de estrutura e conhecimento dos profissionais sobre a temática. Assim é imprescindível o investimento das instituições em educação permanente para os profissionais da saúde, cursos de atualização e treinamentos técnicos, a fim de garantir que as diretrizes do Ministério da Saúde sejam respeitadas e seguidas, dentro do âmbito hospitalar.

\section{Considerações Finais}

Pode-se perceber que os profissionais envolvidos neste estudo, possuíam um entendimento superficial sobre os direitos das parturientes. Observa-se a deficiência de conhecimento acerca das leis que asseguram os direitos das parturientes e a humanização do parto. Assim, acredita-se que a falta de conhecimento é um dos empecilhos para a aplicabilidade das Leis 11.108 de 07 de abril de 2005 e 11.634 de 27 de dezembro de 2007 nos centros obstétricos.

Assim, faz-se necessário investimentos por parte do Ministério da Saúde para o preparo dos profissionais de saúde e os serviços aos quais estão vinculados para a implementação e a aplicação dos direitos das parturientes. Ressalta-se a importância de treinamentos, capacitações e educação permanente nas instituições, no intuito de informar sobre as Leis do governo.

A luta pela humanização do parto nos hospitais requer maiores investimentos por parte dos profissionais de saúde, gestores e comunidade. Identifica-se neste interim que a aderência dos profissionais às práticas humanizadas é um meio eficaz para a qualidade de atendimento no período gravídico-puerperal.

Observa-se que a promulgação de uma Lei não garante sua aplicabilidade. Outrossim, as leis serão obedecidas quando os profissionais estiverem sensibilizados quanto a sua aplicação e as parturientes cientes de seus direitos, para poderem exigi-los, trabalhando juntos na construção de assistência humanizada.

Espera-se, com este estudo, gerar novas e constantes discussões sobre a humanização do parto e a aplicação dos direitos das parturientes. Ademais, seguir motivando os profissionais da saúde que acreditam e lutam pela qualidade da assistência à mulher no processo de nascimento.

\section{Referências Bibliográficas}

1. Diniz CSG. Humanização da assistência ao parto no Brasil: os muitos sentidos de um movimento. Interface Comun Saúde Educ. 2009;3(1):595-602.

2. koettker JG.Parto domiciliar planejado assistido por enfermeiras.Santa Catarina 2010.135p. Dissertação (Mestrado) Universidade Federal de Santa Catarina. Santa Catarina, 2010.

3. Carvalho VF, Kerber NPC, Azambuja EP, Bueno FF, Silveira RS, Barros AM. Direitos das parturientes: conhecimento da adolescente e acompanhante. Saúde Soc..2014; 23(2).

4. Oliveira ZMLP, Madeira AMF. Vivenciando o parto humanizado: um estudo fenomenológico sob a ótica de adolescentes. Rev. Esc. Enfermagem. 2002; 36(2): 133-14.

5. Silva UG. Educação permanente em saúde: práticas humanizadas no centro obstétrico de um hospital universitário. Dissertação (Mestrado). Unisinos, 2013.

6. Ministério da Saúde(BR). Conselho Nacional de Saúde. Resolução 466 de 2012. Dispõe sobre pesquisa com seres humanos. Brasília; 2012. Disponível em: http://conselho.saude.gov.br/resolucoes/2012/Res0466.pdf. Acesso em: 24 jun 2013.

7. Lopes RCS, Donelli TS, Lima CM, Piccinini CA. O Antes e o Depois: Expectativas e Experiências de Mães sobre 0 Parto. 2005. Psicologia: Reflexão e Crítica. 2005; 18(2):247-254. 
8. Minayo MCS. O desafio do conhecimento: pesquisa qualitativa em saúde. 32ª .ed. São Paulo: Hautec, 2013.

9. Ministério da Saúde (BR). Secretaria de Atenção à Saúde. Departamento de Atenção Básica. Atenção ao pré-natal de baixo risco. Departamento de Atenção Básica. - Brasília (DF): Ministério da Saúde; 2012.

10. BRASIL. Presidência da República. Lei n 11.108, de 07 de abril de 2005. Altera a Lei nº 8.080, de 19 de setembro de 1990, para garantir às parturientes o direito à presença de acompanhante durante o trabalho de parto, parto e pós parto imediato, no âmbito do Sistema único de Saúde - SUS. Brasília (DF) 2005. Disponível em: http://www.planalto.gov.br/ ccivil_03/_Ato2004-2005/2005/Lei/L11108.htm Acessado em: 13 jun 2013.

11. Busanelo J, Kerber NPC, Fernandes GFM, Zacarias CC, Cappellaro J, Silva ME. Humanização do parto e a formação dos profissionais da saúde. Ciencia Cuidado Saúde. 2011; 10(1):169-175

12. Hodnett ED, Gates S, Hofmeyr G, Sakala C. Continuous support for women during childbirth. Cochrane Database of Systematic Reviews 2013, Issue 7.

13. Brüggemann OM, Oliveira ME, Martins HEL, Alves MC, Gayeski ME. A inserção do acompanhante de parto nos serviços públicos de saúde de Santa Catarina, Brasil. Esc. Anna Nery. 2013;17(3):432-438

14. Jéssica SM, Nalú PCK, Adriane MNO, Josefine B, Thais SS, Flávia CP. Inserção do acompanhante no cuidado da adolescente em um centro obstétrico do sul do país. Cienc Cuid Saude. 2011; 10(4):781-788.

15. Longo CSM, Andraus LMS, Barbosa MA. Participação do acompanhante na humanização do parto e sua relação com a equipe de saúde. Rev. Eletr. Enf. [Internet]. 2010;12(2):386-91. Disponível em: http://dx.doi.org/10.5216/ree.v12i2.5266. Acesso em: 06/01/2013

16. BRASIL. Presidência da República. Lei $n^{0}$. 11.634, de 27 de dezembro de 2007. Dispõe sobre o direito da parturiente ao conhecimento e a vinculação à maternidade onde receberá assistência no âmbito do Sistema Único de Saúde. Diário Oficial da União: Brasília (DF), 2007. Disponível em: http://www.planalto.gov.br/ccivil_03/_Ato2007-2010/2007/Lei/ L11634.htm. Acessado em: 13 jun 2013.

17. Reis AE, Patrício ZM. Aplicação das ações preconizadas pelo Ministério da Saúde para o parto humanizado em um Hospital de Santa Catarina. Ciência \& Saúde Coletiva. 2005;10 (sup):221-230.

18. Oliveira ASS, Rodrigues DP, Guedes MVC, Felipe GF, Galiza FT, Monteiro LC. O acompanhante no momento do trabalho de parto e parto: percepção das puérperas. Cogitare Enferm. 2011; 16(2):247-53

\section{Natália Timm Aires}

Endereço para correspondência - Rua: Gomes Carneiro, nº 01, Sala 201, CEP 96010-610, Cidade: Pelotas, RS, Brasil.

E-mail: nathytimm@hotmail.com

Lattes: http://lattes.cnpq.br/7050376287461266

Sonia Maria Kongzen Meincke - meinckesmk@gmail.com

Ana Candida Lopes Corrêa - analopescorrea@hotmail.com

Camila Neumaier Alves - camilaenfer@gmail.com

Rita Fernanda Monteiro Fernandes - feunipampa@hotmail.com

Josiane Santos Palma - josiane.enfermeira@hotmail.com

Greice Carvalho de Matos - greicematos1709@hotmail.com

Marilu Correa Soares - enfmari@uol.com.br

Enviado em 19 de novembro de 2014. Aceito em 07 de abril de 2015. 
